\title{
KONSEP ISLAMIC ETHIC MARKETING DI PERBANKAN SYARIAH
}

\author{
Hendra Cipta \\ IAIN Syaikh Abdurrahman Siddik Bangka Belitung
}

Email: hendracipta@iainsasbabel.ac.id

\begin{abstract}
Marketing is part of muamalah in Islam which if carried out based on Islamic ethical norms based on the Qur'an and hadiths will become worship even though marketing is not related to mahdah worship. The article describes the concept of marketing based on Islamic ethics, also known as Islamic morals. The concept of Islamic ethic marketing is offered in the hope that it can be applied in marketing Islamic banks because it is based on the principle of welfare. This concept is offered so that future marketing operations of Islamic banks welfare (falah) in terms of education and protection for the welfare of the community.
\end{abstract}

Keywords: Islamic ethic marketing, sharia banking

\begin{abstract}
Abstrak
Pemasaran merupakan bagian dari muamalah dalam Islam yang jika dilakukan berbasis norma etika Islami yang berlandaskan kepada al-Qur'an dan hadis akanmenjadi ibadah walaupun pemasaran tidak berkaitan dengan ibadah mahdah. Artikel memaparkan konsep pemasaran yang berlandasakan kepada etika Islami yang dikenal juga dengan akhlak Islami. Konsep Islamic ethic marketing ini ditawarkan dengan harapan bisa diterapkan dalam pemasaran bank syariah karena berdasarkan prinsip kemaslahatan. Konsep ini ditawarkan agar operasional pemasaran bank syariah mendatang kemaslahatan (falah) dari sisi edukasi dan perlindungan bagi kemaslahatan masyarakat.
\end{abstract}

Kata Kunci: Islamic ethic marketing, bank syariah 


\section{A. PENDAHULUAN}

Kesatuan antara ekonomi dan akhlak dalam ekonomi Islam sangat erat kaitannya, karena dalam ekonomi Islam terdapat implementasi keimanan dan etika (akhlak) mulia dalam transaksi perekonomian baik dari sisi bisnis maupun fungsi sosialnya. Tujuan dalam transaksi perekonomian dalam ekonomi Islam bukan hanya untuk mengejar keuntungan saja, tapi juga terdapat tujuan untuk "keuntungan" ukhrawi, karena Islam adalah rahmat bagi seluruh alam, maka nilai-nilai kemaslahatan harus diimplementasikan pada setiap aktivitas perekonomian dalam Islam. ${ }^{1}$

Keunikan ekonomi Islam yang menyatukan dimensi dunia dan akhirat melalui implementasi ekonomi yang sesuai dengan kaidah syariah dan akhlak ini menarik perhatian para ekonom, sehingga Jack Aster seorang penulis berkewarganegaraan Perancis mengatakan bahwa orang Islam sudah nyaman dengan sistem ekonomi Islam yang mengimplementasikan nilai ibadah dan akhlak, oleh karena itu besar kemungkinan orang Islam menolak kapitalisme. Aster menambahkan, dengan adanya al-Qur'an sebagai pandangan hidup orang Islam yang di dalamnya terdapat nilai-nilai kebajikan, maka semakin membuat orang Islam tidak akan menoleh ke kapitalisme. Implementasi akhlak dalam aktivitas perekonomian ini merupakan hal baru yang menyadarkan umat manusia akan nafsu ingin mendapatkan keuntungan dalam setiap transaksi bisnis tapi mengabaikan moralitas. ${ }^{2}$

Implementasi nilai-nilai syariah dan akhlak dalam ekonomi Islam $^{3}$ tertata dalam konsep yang rapi dan dipraktekkan dalam transaksi bank

1 Yusuf Qardhawi, Peran Nilai dan Moral dalam Perekonomian Islam, ed. by Didin Hafiduddin dkk (Jakarta: Robbani Press, 1995), hlm. 57.

2 Ibid., hlm. 61.

${ }^{3}$ Zainul Arifin, Dasar-dasar Manajemen Bank Syariah (Jakarta: Pustaka Alvabet, 2005), hlm. 12. 
syariah yang mengabaikan suku bunga dalam transaksi bisnisnya, karena bunga sudah ditetapkan berdasarkan fatwa Majelis Ulama Indonesia (MUI) No. 1 tahun 2004 sebagai transaksi yang terdapat unsur ribawi dan haram hukumnya bertransaksi dengan sistem bunga karena dianggap sebagai riba nasi'ah. ${ }^{4}$ Keharaman riba ${ }^{5}$ ini juga karena terdapat kezaliman dalam sistem ribawi. ${ }^{6}$ Implementasi nilai-nilai syariah dan akhlak dalam ekonomi Islam ini yang menjadi pembeda antara ekonomi Islam dengan kapitalisme dan bank syariah dengan bank konvensional. ${ }^{7}$

Implementasi akhlak dalam transaksi bisnis ekonomi Islam akan berpengaruh terhadap tingkat keuntungan suatu perusahaan, 8 karena dengan implementasi akhlak tersebut akan membuat konsumen merasa dilayani dengan nyaman dan tentunya perusahaan tersebut akan dikenal dari sisi positif.

Ekonomi Islam yang berbasis akhlak ini menanamkan nilai-nilai amanah, berkata benar, bersikap adil, transaksi yang terbebas dari paksaan, transaksi yang humanis dan ramah. Penerapan nilai-nilai ini dalam transaksi bisnis yang berbasis akhlak dalam ekonomi Islam tentunya akan memberikan nilai lebih dalam sistem keuangan Islam dibandingkan dengan sistem konvensional. ${ }^{9}$

\footnotetext{
${ }^{4}$ Majelis Ulama Indonesia, Fatwa Majelis Ulama Indonesia No. 1 Tahun 2004 (2004), hlm.
} 434.

${ }^{5}$ Abul 'Ala Al-Maududi, Ar-Riba (t.tp: Dar al-Fikr, t.t), hlm. 38.

${ }^{6}$ Ummi Kalsum, 'Riba dan Bunga Bank dalam Islam (Analisis Hukum dan Dampaknya Terhadap Perekonomian Umat)', Al-'Adl, vol. 7, no. 2 (2014), hlm. 67-83, ejournal.iainkendari.ac.id/index.php/al-adl/article/view/220/210.

7 Abdullah Saeed, Menyoal Bank Syariah: Kritik Atas Interpretasi Bunga Bank Kaum Neo- Revivalis, ed. by Arif Maftuhin (Jakarta: Paramadina, 2004), hlm. 68.

8 Laili Latifah Puspitasari, 'Analisis Penerapan Etika Bisnis Islam terhadap Tingkat Profitabilitas Rumah Yoghurt Berdasarkan Perspektif Karyawan', UIN Maulana Malik Ibrahim Malang (2014), etheses.uin-malang.ac.id/1883/12/10520034_Ringkasan.pdf.

9 Erly Juliyani, 'Etika Bisnis dalam Persepektif Islam', Ummul Qura, vol. VII, no. 1 (2016), hlm. 63-74, https://ejournal.insud.ac.id/index.php/ummulquro/article/download/92/50. 
Seiring dengan perkembangan zaman dan maraknya jual beli secara online saat ini, maka implementasi akhlak dalam transaksi bisnis semakin penting untuk diterapkan karena bisa menghindari perilaku zalim, curang dan berbohong. ${ }^{10}$ Perilaku tidak terpuji ini bisa saja dilakukan oleh penjual maupun pembeli, maka jika nilai-nilai akhlak Islami ini diterapkan tentunya akan membuat transaksi yang dilakukan menyenangkan bagi penjual dan pembeli.

Dalam menghadapi persaingan global dan lokal bank syariah di Indonesia tentunya harus mampu melakukan berbagai terobosan untuk bisa bersaing dengan bank syariah luar negeri dan lokal. ${ }^{11}$ Salah satu bentuk persaingan tersebut adalah dalam bidang pemasaran, bank syariah yang tidak mempersiapkan perencanaan pemasaran yang matang dan terorganisir tentunya akan tersingkir dalam persaingan.

Bank syariah dalam memasarkan produknya kepada masyarakat harus mampu meyakinkan calon konsumennya untuk mau bertransaksi dan menjadi nasabah di bank syariah tersebut. Tentunya strategi pemasaran yang dilakukan harus inovatif dan menekankan akhlak Islami. ${ }^{12}$

\section{B. KONSEP AKHLAK}

Akhlak merupakan perilaku, karakter dan kepribadian seseorang yang terkait dengan norma, moralitas dan nilai-nilai kebajikan. Jika hal ini tercermin dalam perilaku dan tindakan seseorang maka orang tersebut

10 Biuty Wulan Octavia, 'Tinjauan Hukum Islam terhadap Jual Beli Akad As-Salam dengan Sistem On Line', WAIN Walisongo library.walisongo.ac.id/digilib/files/disk1/117/jtptiain-gdl-biutywulan-5826-1-072311030.pdf.

11 Imam Mukhlis, 'Kinerja Keuangan Bank dan Stabilitas Makroekonomi terhadap Profitabilitas Bank Syariah di Indonesia', Jurnal Keuangan dan Perbankan, vol. 16, no. 2 (2012), hlm. 275-285, jurnal.unmer.ac.id/index.php/jkdp/article/download/1068/705.

12 Firman K. Yulianto dkk, 'Analisis Pengaruh Faktor Bauran Pemasaran terhadap Pertimbangan Nasabah dalam Memilih Bank Syariah di Kota Medan', Wacana, vol. 13, no. 4 (2010), hlm. 537-551. 
akan dikatakan sebagai orang yang berakhlak mulia. Orang yang jiwanya sudah terdidik melakukan kebajikan, maka ketika ada peluang melakukan kebaikan akan segera melakukan kebaikan walaupun tanpa komando dari orang lain. ${ }^{13}$

Rasulullah menekankan dalam hadisnya bahwa beliau diutus untuk menyempurnakan akhlak umat manusia. Misi Rasulullah ketika diutus Allah untuk memperbaiki akhlak umat manusia ketika itu karena memang keterpurukan moral merajalela saat itu. Dimana hal-hal yang bertentangan dengan syariah banyak terjadi, sehingga dengan datangnya Rasulullah melalui dakwahnya beliau ingin mendakwahkan memperbaiki keterpurukan moral yang sudah kritis. Dalam Islam, akhlak menjadi menjadi salah satu dimensi dalam diri seorang muslim. ${ }^{14}$

Manusia itu terbagi pada dua bentuk:

1. Bentuk lahiriah, hal ini berikaitan dengan bentuk-bentuk fisik manusia dan hal-hal yang terlihat dari dirinya, apakah hal baik ataupun kurang baik.

2. Bentuk batiniah, adalah kebalikan dari bentuk lahiriah. Bentuk batiniah ini terbagi kepada hal yang mengandung kebajikan dan hal yang mengandung keburukan, dan kesemuanya ini tergambar dalam bentuk akhlak umat manusia. ${ }^{15}$

Akhlak terpuji merupakan hasil dari penempaan dari insan muttaqin, hal ini mengindikasikan bahwa manusia tersebut mempunyai keseimbangan antara ibadah dan kehidupan sosialnya. Sedangkan akhlak hlm. 8-9.

${ }^{13}$ Munawar Rahmat, Filsafat Akhlak (Bandung: Celtic Press dan Prodi IPAI UPI, 2016),

14 Nixson Husin, 'Hadits-hadits Nabi SAW. Tentang Pembinaan Akhlak', An-Nur, vol. 4, no. 1 (2015), hlm. 14-40.

15 Muhammad bin Shalih al-'Utsaimin, Makarim al-Akhlaq, (t.tp: Madar al-Wathan linnasyr, t.t), hlm. 7. 
yang tidak terpuji merupakan cerminan dari terperangkapnya manusia tersebut ke dalam bujuk rayuan setan, sehingga melakukan perbuatan tercela dan tidak terpuji. ${ }^{16}$

Menurut Al-Ghazali manusia akan memperoleh predikat berakhlak mulia jika mampu mengontrol ilmu, amarah, nafsu syahwat dan menyeimbangkan tiga instrumen ini. Ilmu terkontrol menuju kepada kebaikan akan melahirkan hikmah dan hal-hal positif dari penerapan ilmu pengetahuan tersebut. Sementara nafsu amarah yang terkontrol akan menghasilkan tindakan yang bijak yang tidak berlandaskan pada emosi amarah. Sedangkan nafsu syahwat akan terkontrol jika diarahkan oleh ilmu agama dan akal pikiran yang sehat. ${ }^{17}$

Berdasarkan sasarannya implementasi akhlak tersebut terbagi pada akhlak kepada Allah sebagai rabb manusia dan akhlak dalam berinteraksi antara sesama manusia. Jika dianalogikan kepada sebuah pohon, maka antara akhlak, akidah dan syariah terwujud kepada akar, pohon dan buah dari pohon tersebut. Akidah menjadi akar dari akhlak tersebut dan syariah terwujud dalam pohon, sedangkan buah yang dihasilkan dari pohon tersebut adalah akhlak. ${ }^{18}$ Artinya buah dari pohon tersebut akan terasa enak jika bersumber dari akar dan pohon yang bagus dan akhlak akan menjadi mulia dan terpuji jika dilandasi oleh akidah dan nilai-nilai syariah.

Berbicara tentang akhlak, tidak hanya berbicara kaitan antara akhlak dengan ibadah dari segi shalat, ibadah, puasat zakat dan ibadah lainnya; tapi dalam Islam akhlak juga berkaitan dengan muamalah antar sesama

\footnotetext{
${ }^{16}$ Syamsul MZ Rizal, 'Akhlak Islami Persepktif Ulama Salaf', Edukasi Islam, Jurnal Pendidikan vol. 07, no. 1 (2018), hlm. 67-100.

17 Agus Salim Lubis, 'Konsep Akhlak dalam Pemikiran al-Ghazali', Jurnal Hikmah, vol. Volume VI, no. Nomor 01 (2012), hlm. 58-67.

18 Syarifah Habibah, 'Akhlak Dan Etika Dalam Islam', Jurnal Pesona Dasar, vol. 1, no. 4 (2015), hlm. 73-87.
} 
manusia dalam kehidupan sehari-hari yang berkaitan dengan perekonomian, hukum, politik dan bidang kehidupan lainnya. Dalam bidang ekonomi lebih spesifik lagi akhlak berkaitan dengan akhlak dalam perdagangan, bertetangga, konsumtif, distributif dan pemasaran. ${ }^{19}$

Lebih detailnya Islam mengatur akhlak manusia kepada Allah, akhlak kepada sesama manusia dan akhlak kepada alam beserta isinya. Akhlak kepada Allah mencakup:

1. Perintah kepada hal-hal yang diperintahkan Allah dan menjauhi segala larangan-Nya

2. Bertanggung jawab terhadap amanah yang telah diberikan Allah kepada umat manusia dengan menjaga amanah tersebut sebaikbaiknya.

3. Selalu minta ampun dan bertaubat kepada Allah atas segala kesalahan dan kekhilafan yang dilakukan.

4. Bersungguh-bersungguh dalam mencapai keridhaan Allah.

5. Selalu tekun dalam beribadah kepada Allah dalam bentuk ibadah mahdhah dan sebaliknya.

Sedangkan akhlak antar sesama manusia adalah senantiasa saling menghormati dan menghargai orang lain, dan akhlak terhadap alam beserta isinya adalah dengan selalu menjaga, merawat dan melestarikan alam tempat manusia tinggal dan tidak menyakiti makhluk hidup lain. ${ }^{20}$

19 Mahmud Thohier, 'Kajian Islam Tentang Akhlak dan Karakteristiknya', Jurnal Mimbar, vol. Volume XXI, no. Nomor 1 (2007), hlm. 1-14.

20 Nurhayati, 'Akhlak Dan Hubungannya Dengan Aqidah Dalam Islam', Jurnal Mudarrisuna, vol. 4, no. 2 (2014), hlm. 289-309. 


\section{KONSEP PEMASARAN BERBASIS AKHLAK ISLAMI}

Islam melalui syariatnya memberikan aturan di semua sisi penting kehidupan umat manusia. ${ }^{21} \mathrm{Hal}$ ini dikarenakan syariat Islam ingin memberikan kesempurnaan pada kehidupan umat manusia dengan memberikan perlindungan akidah dari berbagai penyimpangan, memerdekakan umat manusia dari belenggu perbudakan, serta menjadikan mereka terhubung dengan Pencipta dan Pemberi rizkinya. ${ }^{22}$

Menjaga harta agar tetap bersih dan suci adalah salahsatu hal penting yang disampaikan dalam maqashid syariah, karena bagi seorang muslim harta adalah sarana untuk beribadah ghairu mahdah. Menurut mazhab Hanafiyah harta akan mempunyai makna dan nilai jika penggunaannya sesuai dengan tuntunan syariat. ${ }^{23}$

Kota Mekah dalam sejarahnya tidak hanya dikenal sebagai kiblat umat muslim dimanapun di dunia, tapi juga dikenal sebagai kota sentral perdagangan pada masa Rasulullah. Aktivitas ibadah dilakukan di dalam Masjidil Haram yang terletak di kota Mekah sedangkan aktivitas perekonomian tumbuh dan berkembang pasar-pasar dan pusat perdagangan di luar masjid. Sampai saat ini masih banyak ditemukan tokotoko dan pasar di sekitar area Masjidil Haram. Para pedagang sekitar Masjidil Haram melihat potensi pasar dari para jamaah haji dan umrah yang datang dari berbagai penjuru dunia untuk beribadah di Masjidil Haram Mekah. ${ }^{24}$

\footnotetext{
${ }^{21}$ Hal ini bisa dilihat dari teori maqasid al-Syari'ah yang terdiri dari memelihara agama, memelihara jiwa, memlihara akal, memelihara keturunan, dan memelihara harta. Fathurrahman Djamil, Filsafat Hukum Islam (Jakarta: Logos Wacana Ilmu, 1999), hlm. 123-131.

${ }^{22}$ Abdullah Abdul Husain at-Tariqi, Ekonomi Islam Prinsip, Dasar, dan Tujuan, ed. by M. Irfan Syofwani (Yogyakarta: Magistra Insania Press, 2004), hlm. 1.

${ }^{23}$ Abdullah al-Mushlih, Fikih Ekonomi Keuangan Islam, ed. by Abu Umar Basyir (Jakarta: Darul Haq, 2004), hlm. 73.

${ }^{24}$ Musa Asy'arie, Islam Etos Kerja dan Pemberdayaan Ekonomi Umat (Yogyakarta:
} 
Pemasaran Islami merupakan pemasaran berbasis ibadah (sesuai dengan tujuan diciptakannya manusia). Setiap aspek dalam bermuamalah harus sesuai dengan tuntunan syariat yang sudah dijelaskan melalui alQur'an dan hadis dan jika ini dilakukan maka akan menjadi ibadah bagi seorang muslim walaupun yang dilakukannya perkara muamalah yang tidak berhubungan langsung dengan ibadah mahdah. Sederhananya, Islam menghendaki aktivitas transaksi perdagangan tidak hanya sekedar penjual mendapatkan keuntungan dengan barang dagangannya dan pembeli memperoleh barang yang dibelinya, tapi perdagangan dalam Islam akan menjadi ibadah jika mematuhi tuntunan syariat yang tertuang dalam alQur'an dan hadis. ${ }^{25}$

Berdasarkan benang merah di atas, maka dapat dikatakan pemasaran Islami merupakan proses pemasaran yang mengedepankan produk-produk halal dan baik (thoyyibah) untuk mencapai kesejahteraan bersama antara penjual dan pembeli, kesejahteraan yang diperoleh tidak hanya untuk keuntungan material saja; tapi juga untuk kemaslahatan spritual di dunia maupun di akhirat. ${ }^{26}$ Jika perdagangan dan pemasaran dilakukan dengan mematuhi aturan syariah, maka akan menjadi ibadah dan akan memperoleh kemaslahatan di akhirat.

Proses pemasaran dan transaksi perdagangan dikatakan Islami jika operasionalnya mengimplementasikan hal-hal berikut ini:

1. Jika operasional pemasaran dilakukan dengan mengedepankan akhlak dan moralitas. Islam menghendaki operasional pemasaran dilakukan dengan berlandaskan keadilan

\footnotetext{
LESFI, 1997), hlm. 59-60.

${ }^{25}$ Golam Mohiuddin and Shariful Haque, 'Marketing Ethics in Islam: A Model Based Theoretical Study', Human Resource Management Research, vol. 3, no. 3 (2013), hlm. 95-100. ${ }^{26}$ Ibid.
} 
bagi semua pihak. Oleh karena itu, Islam tidak menganjurkan terdapat penipuan dan penimbunan untuk menaikkan harga barang karena hal ini menyalahi moralitas.

2. Operasional pemasaran harus mengedepankan keadilan bagi individu dan keadilan bagi sosial masyarakat. ${ }^{27}$ Oleh karena itu alQur'an melarang melakukan transaksi yang merugikan orang lain sebagaimana firman Allah dalam surat An-Nisa ayat 29:

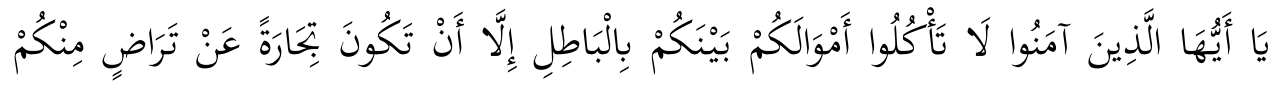

$$
\begin{aligned}
& \text { وَلَا تَفْتُلُوا أَنْفُسَكُكْم إِنَّ المََّ كَانَ بِكُمْ رَحِيمًا (29) }
\end{aligned}
$$

Dalam ayat ini Allah mengingatkan untuk menghindari transaksi yang dilarang oleh syariat Islam (yang dikatakan dalam ayat jangan memakan harta dengan cara yang batil). Jika dalam suatu transaksi terdapat unsur riba, maysir, penipuan dan merugikan orang lain, maka transaksi tersebut masuk ke dalam kategori yang disampaikan dalam ayat ini. ${ }^{28}$ Berdasarkan surat An-Nisa ayat 29 adalah salah satu contoh dari transaksi muamalah jika dilakukan sesuai dengan aturan syariah akan menjadi ibadah bagi seorang muslim.

3. Terhindar dari penyelundupan barang dagangan dan black market, penipuan, manipulasi dan kebohongan yang dilakukan dalam proses pemasaran danpemasaran barang-barang yang tidak legal.

27 Ibid.

28 Al-Imam Abul Fida Ismail Ibnu Kasir, Tafsir Ibnu Kasir, 5th edition (t.tp: Sinar Baru, t.t), hlm. $37-39$. 
4. Terhindar dari hal-hal mubazir dan boros baik secara makro maupun mikro ekonomi. ${ }^{29}$ Sebagaimana sudah diingatkan Allah dalam surat Al-Isra' ayat 27:

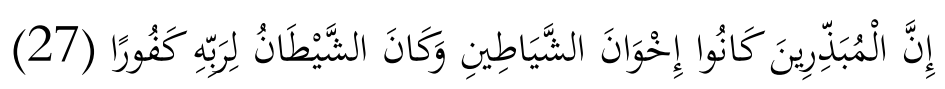

Menurut Quraish Shihab kata boros (المبذرين) dalam ayat ini berkaitangan dengan pengeluaran yang dilakukan. Jika seseorang berbelanja dalam kuantitas yang banyak tapi untuk hal yang bermanfaat, maka tidak dianggap sebagai pemborosan. Namun, jika pengeluaran dan belanja dilakukan untuk hal-hal yang tidak ada manfaatnya maka inilah yang disebut dengan pemborosan walaupun pengeluarannya sedikit. ${ }^{30}$

5. Rasulullah menyarankan kepada setiap muslim agar jujur dalam melakukan aktivitas bisnisnya. Rasulullah menyatakan bahwa pedagang yang jujur akan mendapat tempat di surga pada hari akhir nanti. ${ }^{31}$ Makna kejujuran berkaitan dengan ucapan (menjaga tutur kata dari kebohongan dan ketidakjujuran), tindakan (menjaga sikap dan tindakan dari hal-hal yang bertentangan syariat) dan keadaan (selalu bersikap ikhlas baik dalam perkataan, tindakan dan hati). ${ }^{32}$

6. Islam melarang melakukan hal-hal spekulatif dalam transaksi bisnis dan pemasaran serta melarang melakukan penimbunan

${ }^{29}$ Mohiuddin and Haque, 'Marketing Ethics in Islam: A Model Based Theoretical Study', hlm. $95-100$.

${ }^{30}$ M. Quraisy Shihab, Tafsir al-Mishbah: Pesan, Kesan dan Keserasian al-Qur'an, 7th edition (Jakarta: Lentera Hati, 2002), hlm. 459.

31 Mohiuddin and Haque, 'Marketing Ethics in Islam: A Model Based Theoretical Study', hlm. $95-100$.

32 Almunadi, 'Shiddiq dalam Pandangan Quraish Shihab', Jurnal JIA, vol. 17, no. 1 (2016), hlm.127 - 138. 
barang dagangan dengan maksud agar harga menjadi naik. Pemasaran produk dan barang yang belum ada juga dilarang dalam Islam karena adanya ketidakpastian dalam wujud dan bentuk barang yang diperdagangkan.

7. Islam menganjurkan pembayaran zakat dalam transaksi bisnis (khususnya zakat mal), jadi selain untuk memperoleh keuntungan dalam bisnis; Islam juga menganjurkan untuk melakukan ibadah sosial melalui penyaluran zakat dari keuntungan bisnis. ${ }^{33}$ Allah menegaskan pada harta orang-orang kaya terdapat hak para fakir miskin sebagaimana firman-Nya pada surat Adz-Dzariyat ayat 19:

$$
\text { وَفِ أَمْوَالهِمْ حَقُقُ لِلسَّائِلِل وَالْمَحْرُوْر }
$$

Kata (لِسَّائلِل) dalam ayat ini bermakna peminta-minta karena mempunyai kekurang mampuan dalam bidang ekonomi. Sedangkan (الْمَحُرُوحم) dalam ayat ini adalah pengangguran yang tidak mempunyai pekerjaan dan orang yang tidak mempunyai keahlian apapun dalam suatu profesi sehingga tidak mempunyai penghasilan. ${ }^{34}$

8. Islam mengharuskan mengimplementasikan akhlak dan moralitas pada setiap aktivitas dan tindakan manusia termasuk juga dalam hal operasional pemasaran. Hal ini disebabkan karena umat Muhammad adalah umat terbaik sebagaimana yang

33 Mohiuddin and Haque, 'Marketing Ethics in Islam: A Model Based Theoretical Study', hlm. 95 - 100 .

${ }^{34}$ Ibnu Katsir, Tafsir Surat Adz-Dzariyat, ayat 15-23 (2015), http://www.ibnukatsironline.com/2015/10/tafsir-surat-adz-dzariyat-ayat-15-23.html, diakses tanggal 1 Mei 2018. 
disampaikan Allah dalam surat Ali Imran ayat 110:35

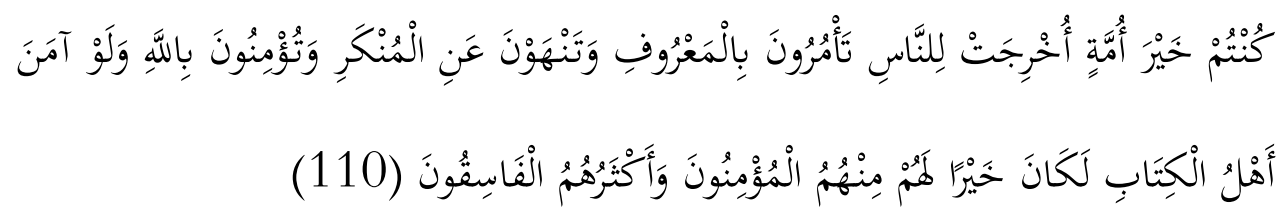

Ayat ini menyatakan bahwa umat Muhammad adalah umat terbaik karena imannya kepada Allah dan karena menyeru kepada

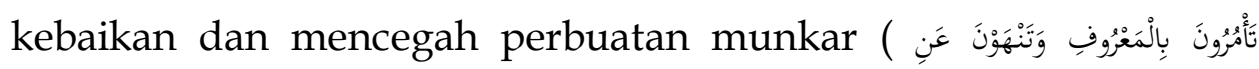

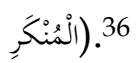

Ekonomi Islam mendasarkan sistem perekonomiannya kepada empat prinsip kemaslahatan, yaitu:

1. Transaksi perdagangan bersinergi dengan akhlak muslimin dan lingkungan sehingga setiap transaksi bisnis yang dilakukan menimbulkan kemaslahatan bagi setiap manusia dan lingkungan sekitarnya.

2. Berbasis keadilan yang seimbang kepada setiap individu yang terlibat dalam bisnis, baik dari sisi produsen, konsumen dan distributor. Jangan sampai ada salahtu pihak yang dirugikan sehingga tidak muncul keadilan.

3. Transparansi kepada setiap individu yang terlibat dalam transaksi bisnis, jangan sampai ada informasi yang ditutupi sehingga merugikan pihak yang tidak mendapatkan informasi.

4. Berbasis kebebasan, jangan sampai ada individu yang terpaksa melakukan transaksi bisnis karena dipaksa oleh pihak lain.

35 Mohiuddin and Haque, 'Marketing Ethics in Islam: A Model Based Theoretical Study', hlm. 95 - 100 .

36 M. Quraish Shihab, Al Lubab: Makna, Tujuan, dan Pelajaran dari Surah- Surah Al Qur'an (Tanggerang: Lentera Hati, 2012), hlm. 127. 
Kebebasan bukan tanpa batas, tapi kebebasan disini juga memperhatikan kemaslahatan umat manusia lainnya. ${ }^{37}$

Kebebasan dalam pemasaran dan transaksi bisnis adalah fondasi utama dalam ekonomi Islam. Kebebasan ini harus dilandasi tentang responsibilitas agar tidak melewati batas-batas kebebasan. ${ }^{38}$ Responsibilitas ini sangat ditekankan dalam ajaran Islam sebagaimana yang disampaikan dalam al-Qur'an maupun hadis Rasulullah SAW.39 Allah menegaskan dalam surat Al-Mudassir ayat 38 tentang tanggung jawab setiap individu:

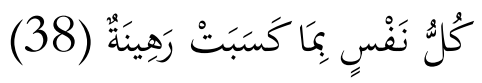

Ciri orang yang sudah bertanggung jawab adalah jika dirinya sudah bertanggung jawab kepada Allah, maka secara otomatis akan bertanggung jawab juga terhadap dirinya sendiri dan kepada lingkungan sekitarnya. ${ }^{40}$ Tanggung jawab kepada Allah melebihi tanggung jawab dari sisi apapun, karena berkaitan dengan ibadah dan tanggung jawab sosial seseorang dalam bermuamalah juga menjadi tanggung jawab individu kepada Allah.

Abul Hasan, Abdelkader Chachi dan Salma Abdul Latiff dalam hasil penelitiannya menemukan bahwa implementasi pemasaran Islami berbasis akhlak akan meningkatkan standar perilaku dan sikap antara bankir bank syariah dan nasabah. Implementasi pemasaran Islami berbasis akhlak ini

\footnotetext{
37 Syed Nawab Haider Naqvi, Etika dan Ilmu Ekonomi Suatu Síntesis Islami (Bandung: Mizan, 1985), hlm. 96.

38 Akhmad Nur Zaroni, ‘Bisnis Dalam Perpsektif Islam (Telaah Aspek Keagamaan dalam Kehidupan Ekonomi)', Mazahib, vol. 4, no. 2 (2007), hlm. 172-84, https://journal.iain-samarinda.ac.id/index.php/mazahib/article/view/507.

39 Monzer Kahf, Ekonomi Islam (Telaah Analitik Terhadap Fungsi Sistem Ekonomi Islam), ed.by Machnun Husein (Yogyakarta: Pustaka Pelajar, 1995), hlm. 51.

40 Asroful Kadafi dan M. Ramli, 'Integrated QS al Mudatsir in The Reality Group Conseling to Grow The Character of Students Academic Responsibility', Jurnal Ilmiah Counsellia, vol. $7, \quad$ no. 2 (2017), hlm. 117-25, http://ejournal.unipma.ac.id/index.php/JBK/article/view/1867/1413.
} 
akan meningkatkan rasa saling percaya antara nasabah dengan bankir bank syariah. $^{41}$

\section{DAMPAK DARI IMPLEMENTASI KONSEP YANG DITAWARKAN}

Dampak yang diharapkan dari konsep etika persaingan dan pemasaran Islam di atas adalah agar tidak terjadi praktik bisnis yang menyalahi akhlak Islami dan "cita-cita" pengembangan Perbankan Syari'ah yang disampaikan oleh Bank Indonesia.

Praktik bisnis Islami ini berpatokan pada pandangan ekonomi Islam tentang kesejahteraan yang didasarkan atas keseluruhan ajaran Islam tentang kehidupan ini. Secara singkat kesejahteraan menurut ajaran Islam mencakup dua pengertian, yaitu:

1. Kesejahteraan holistik dan seimbang, yaitu mencakup dimensi material maupun spiritual serta mencakup individu maupun sosial. Sosok manusia terdiri atas unsur fisik dan jiwa, karenanya kebahagiaan haruslah seimbang di antara keduanya. Demikian pula manusia memiliki dimensi individual, tetapi tentu saja ia tidak dapat terlepas dari lingkungan sosial. Manusia akan merasa bahagia jika terdapat keseimbangan di antara dirinya sendiri dengan lingkungan sosialnya.

2. Kesejahteraan di dunia maupun di akhirat, sebab manusia tidak hanya hidup di alam dunia saja tetapi juga di alam setelah kematian/kemusnahan dunia (akhirat). Jika kondisi ideal ini tidak dapat dicapai maka kesejahteraan di akhirat tentu lebih

${ }^{41}$ Abul Hassan, Abdelkader Chachi, dan Salma AbdulLatiff, 'Islamic Marketing Ethics and Its Impact on Customer Satisfaction in the Islamic Banking Industry', Journal of King Abdulaziz University- Islamic Economics, vol. 21, no. 1 (2008), hlm. 27-46, http://prod.kau.edu.sa/centers/spc/jkau/Data/Review_Artical.aspx?No=2606. 
diutamakan, sebab ia merupakan suatu kehidupan yang abadi dan lebih bernilai (valuable) dalam segala hal. ${ }^{42}$

Istilah umum yang banyak digunakan untuk menggambarkan kesejahteraan hakiki ini -suatu keadaan hidup yang sejahtera secara material- spiritual pada kehidupan di dunia maupun akhirat dalam bingkai ajaran Islam adalah falah. Dalam pengertian literal, falah adalah kemuliaan dan kemenangan, yaitu kemuliaan dan kemenangan dalam hidup. Dalam pengertian agama Islam, falah meliputi konsep kebahagiaan yang bersifat dunia dan akhirat. Untuk kehidupan dunia, falah mencakup tiga pengertian, yaitu kelangsungan hidup (survival), kebebasan berkeinginan (freedom from want) serta kekuatan dan kehormatan (power and honour). Sedangkan itu untuk kehidupan akhirat, falah mencakup pengertian kelangsungan hidup yang abadi (eternal survival), kesejahteraan abadi (eternal prosperity), kemuliaan abadi (everlasting glory)

42 Ekonomi umat menjadi perhatian Rasulullah saw, karena masalah ekonomi merupakan pilar penyangga keimanan yang harus diperhatikan. Sebagaimana yang diriwayatkan oleh Muslim, Rasulullah bersabda "kemiskinan membawa orang kepada kekafiran". Maka upaya untuk mengentaskan kemiskinan merupakan bagian dari kebijakan-kebijakan sosial dan ekonomi yang dikeluarkan Rasulullah saw. Misi mulia Rasulullah saw di muka bumi ini adalah membangun masyarakat yang beradab. Langkah pertama yang dilakukan adalah mengkonstruksi secara mendasar pemahaman manusia terhadap keberadaannya di dunia. Rasulullah saw menganjurkan agar manusia saling menghormati dan menyayangi dalam penyelenggaraan hidupnya sesuai dengan al-Qur'an dan al-hadits. Rasulullah saw melarang manusia melakukan tindakan yang melanggar nilai-nilai agama karena alasan kemuliaannya di dunia, jabatan, kekayaan atau lainya. Sebab apapun yang dilakukan manusia akan sia-sia karena pada hakekatnya manusia yang mulia dilihat dari sisi ketakwaannya. Asghar Ali Engineer, Revolusi Negara Islam (terj), (Yogyakarta: Pustaka Pelajar, 2000), hlm. 99139, mengutip pernyataan al-Ghazali dalam Ihya' Ulumuddin: "Di jaman kamu, semua atau hampir semua harta kekayaan penguasa dimiliki secara tidak halal. Mengapa demikian, karena hanya zakat, khums, dan rampasan perang sajalah yang halal, namun semua itu kini tidak ketahuan rimbanya. Yang tersisa kini hanya jizyah (sumber pendapatan yang sah), itupun di tagih dengan cara kekerasan dan karenanya menjadi tidak halal". Mengenai kunjungan terhadap raja, al-Ghazali mengatakan:"Kita harus menjauhi mereka (para penguasa) agar kita tidak sampai bertemu (dengan mereka) dan ini wajib hukumnya karena inilah satu-satunya cara untuk menjaga agama kita." Lihat juga Shirteen T. Hunter (ed), Politik Kebangkitan Islam, Keragaman dan Kesatuan, (Yogyakarta: Tiara Wacana, 2001), hlm. 5. Lihat juga tulisan Hendra Cipta dalam Zulkifli dkk., Pernakpernik Wacana Baru Islam, (Jogjakarta: Ar-Ruzz Media, 2010), hlm. 163-164. 
dan pengetahuan yang bebas dari segala kebodohan (knowledge free of all ignorance).

Falah mencakup aspek yang lengkap dan menyeluruh bagi kehidupan manusia. Aspek ini secara pokok meliputi spiritualitas dan moralitas, ekonomi, sosial dan budaya, serta politik. Misalnya, untuk memperoleh suatu kelangsungan hidup maka dalam aspek mikro manusia membutuhkan (a) pemenuhan kebutuhan biologis seperti kesehatan fisik atau bebas dari penyakit, (b) faktor ekonomis, misalnya memiliki sarana kehidupan, dan (c) faktor sosial, misalnya adanya persaudaraan dan hubungan antar personal yang harmonis. Dalam aspek makro, kesejahteraan menuntut adanya keseimbangan ekologi, lingkungan yang higienis, manajemen lingkungan hidup, dan kerja sama antar anggota masyarakat. Faktor-faktor ini baru akan lengkap jika manusia juga terbebas dari kemiskinan serta memiliki kekuatan dan kehormatan.

Komitmen Islam yang demikian mendalam terhadap persaudaraan dan keadilan menyebabkan konsep kesejahteraan (falah) bagi semua umat manusia sebagai suatu tujuan pokok Islam. Kesejahteraan ini meliputi kepuasan fisik sebab kedamaian mental dan kebahagiaan hanya dapat dicapai melalui realisasi yang seimbang antara kebutuhan materi dan rohani dari personalitas manusia. Karena itu, memaksimumkan output total semata-mata tidak dapat menjadi tujuan dari sebuah masyarakat muslim. Memaksimumkan output, harus dibarengi dengan menjamin usaha-usaha yang ditujukan kepada kesehatan rohani yang terletak pada batin manusia, keadilan serta perdamaian yang fair pada semua peringkat 
interaksi manusia. Hanya pembangunan semacam inilah yang akan selaras dengan tujuan-tujuan syari'ah (maqashid syari'ah). ${ }^{43}$

Sementara itu, dari sisi “cita-cita” pengembangan Perbankan Syari'ah, Bank Indonesia sudah menyusun program pengembangan Perbankan Syari'ah ke depan, namun program pengembangan tersebut harus didukung dengan adanya kesamaan visi dan misi antar sesama praktisi Perbankan Syari'ah. Bank Indonesia sudah melakukan program sosialisasi iB Campaign pada 2011 akan tetap mengedepankan PDB (positioning, differentiation, branding) dari industri perbankan syariah sebagai “Lebih Dari Sekedar Bank" (Beyond Banking), melalui komunikasi yang inklusif dan terfokus tentang kelebihan Bank Syariah dalam hal fitur (functional benefits), keberagaman produk, dan kekayaan variasi skema keuangan yang dimilikinya.

Upaya untuk mengembangkan pasar Perbankan Syariah yang secara efektif juga memiliki dimensi edukasi dan perlindungan masyarakat, Bank Indonesia telah mengembangkan kerangka Market Development Strategic Plan (MDSP) yang berusaha untuk memposisikan industri Perbankan Syariah sebagai salah satu pilar ekonomi nasional yang kokoh di masyarakat. ${ }^{44}$

${ }^{43}$ Umer Chapra, Islam dan Pembangunan Ekonomi, diterjemahkan oleh Ikhwan Abidin (Jakarta: Gema Insani Press, 2000), hlm. 7-8. Lihat juga Pusat Pengkajian dan Pengembangan Ekonomi Islam (P3EI) Universitas Islam Indonesia, Ekonomi Islam, (Jakarta: PT. Raja Grafindo Persada, 2008), hlm. 2-5. Lihat juga Hamzah Ya'qub, Kode Etik Dagang Menurut Islam (Pola Pembinaan Hidup Dalam Berekonomi), (Bandung: CV Diponegoro, 1984), hlm. 13-14.

${ }^{44}$ Bank Indonesia, Outlook ......., hlm. 62-63 


\section{E. SIMPULAN}

Teori pemasaran yang berkembang selama ini perlu diselaraskan dengan konsep syariah (dalam hal ini etika pemasaran Islami), apalagi pemasaran tersebut dilakukan di perbankan syariah sehingga diperlukan konsep yang mengedepankan akhlak Islami agar interaksi pemasaran yang dilakukan antara bank syariah dan calon nasabah tidak hanya berbasis bisnis semata, tetapi juga menjadi ibadah jika dilakukan dengan mengedepankan akhlak islami. 


\section{DAFTAR PUSTAKA}

al-'Utsaimin, Muhammad bin Shalih, 'Makarim al-Akhlaq', in Madar al-Wathan linnasyr, t.tp, p. 7.

Al-Maududi, Abul 'Ala, Ar-Riba, t.tp: Dar al-Fikr.

al-Mushlih, Abdullah, Fikih Ekonomi Keuangan Islam, ed. by Abu Umar Basyir, Jakarta: Darul Haq, 2004.

Almunadi, 'Shiddiq dalam Pandangan Quraish Shihab', Jurnal JIA, vol. 17, no. 1,2016, pp. 127-38.

Arifin, Zainul, Dasar-dasar Manajemen Bank Syariah, Jakarta: Pustaka Alvabet, 2005.

Asy'arie, Musa, Islam Etos Kerja dan Pemberdayaan Ekonomi Umat, Yogyakarta: LESFI, 1997.

at-Tariqi, Abdullah Abdul Husain, Ekonomi Islam Prinsip, Dasar, dan Tujuan, ed. by M. Irfan Syofwani, Yogyakarta: Magistra Insania Press, 2004.

Djamil, Fathurrahman, Filsafat Hukum Islam, Jakarta: Logos Wacana Ilmu, 1999.

Habibah, Syarifah, 'Akhlak dan Etika dalam Islam', Jurnal Pesona Dasar, vol. 1, no. 4, 2015, pp. 73-87.

Hassan, Abul, Abdelkader Chachi, and Salma AbdulLatiff, 'Islamic Marketing Ethics and Its Impact on Customer Satisfaction in the Islamic Banking Industry', Journal of King Abdulaziz University-Islamic Economics, vol. 21, no. 1, 2008, pp. 27-46 [https://doi.org/10.4197/islec.21-1.2].

Husin, Nixson, 'Hadits-hadits Nabi SAW. Tentang Pembinaan Akhlak', An-Nur, vol. 4, no. 1, 2015, pp. 14-40.

Juliyani, Erly, 'Etika Bisnis dalam Persepektif Islam', Ummul Qura, vol. VII, no. 1, 2016, pp.

63-74, https://ejournal.insud.ac.id/index.php/ummulquro/article/download/9 $\underline{2 / 50}$.

Kadafi, Asroful and M. Ramli, 'Integrated QS al Mudatsir in The Reality Group Conseling to Grow The Character of Students Academic Responsibility', 
Jurnal Ilmiah Counsellia, vol. 7, no. 2, 2017, pp. 117-125 [https://doi.org/http://doi.org/10.25273/counsellia.v7i2.1867].

Kahf, Monzer, Ekonomi Islam (Telaah Analitik Terhadap Fungsi Sistem Ekonomi Islam), ed. by Machnun Husein, Yogyakarta: Pustaka Pelajar, 1995.

Kalsum, Ummi, 'Riba dan Bunga Bank dalam Islam (Analisis Hukum dan Dampaknya Terhadap Perekonomian Umat)', Al-'Adl, vol. 7, no. 2, 2014, pp. 67-83, ejournal.iainkendari.ac.id/index.php/aladl/article/view/220/210.

Kasir, Al-Imam Abul Fida Ismail Ibnu, Tafsir Ibnu Kasir, 5th edition, t.tp: Sinar Baru.

Katsir, Ibnu, Tafsir Surat Adz-Dzariyat, ayat 15-23, 2015, http://www.ibnukatsironline.com/2015/10/tafsir-surat-adz-dzariyatayat-15-23.html.

Lubis, Agus Salim, 'Konsep Akhlak dalam Pemikiran al-Ghazali', Jurnal Hikmah, vol. Volume VI, no. Nomor 01, 2012, pp. 58-67.

Majelis Ulama Indonesia, Fatwa Majelis Ulama Indonesia No. 1 Tahun 2004, 2004.

Mohiuddin, Golam and Shariful Haque, 'Marketing Ethics in Islam : A Model

Based Theoretical Study', Human Resource Management Research, vol. 3, no. 3,2013, pp. 95-100 [https://doi.org/10.5923/j.hrmr.20130303.05].

Mukhlis, Imam, 'Kinerja Keuangan Bank dan Stabilitas Makroekonomi terhadap Profitabilitas Bank Syariah di Indonesia', Jurnal Keuangan dan Perbankan, vol.16, no. 2, 2012, pp. 275-285, jurnal.unmer.ac.id/index.php/jkdp/article/download/1068/705.

Naqvi, Syed Nawab Haider, Etika dan Ilmu Ekonomi Suatu Síntesis Islami, Bandung: Mizan, 1985.

Nurhayati, 'Akhlak Dan Hubungannya Dengan Aqidah Dalam Islam', Jurnal Mudarrisuna, vol. 4, no. 2, 2014, pp. 289-309 [https://doi.org/10.22373/jm.v4i2.291].

Octavia, Biuty Wulan, ‘Tinjauan Hukum Islam terhadap Jual Beli Akad As-Salam dengan Sistem On Line', IAIN Walisongo, 
2011, library.walisongo.ac.id/digilib/files/disk1/117/jtptiain-gdlbiutywulan-5826-1-072311030.pdf.

Puspitasari, Laili Latifah, 'Analisis Penerapan Etika Bisnis Islam terhadap Tingkat Profitabilitas Rumah Yoghurt Berdasarkan Perspektif Karyawan', UIN Maulana Malik Ibrahim Malang, 2014 [https://doi.org/10.1192/bjp.205.1.76a].

Qardhawi, Yusuf, Peran Nilai dan Moral dalam Perekonomian Islam, ed. by Didin Hafiduddin dkk, Jakarta: Robbani Press, 1995.

Rahmat, Munawar, Filsafat Akhlak, Bandung: Celtic Press dan Prodi IPAI UPI, 2016.

Rizal, Syamsul MZ, 'Akhlak Islami Persepktif Ulama Salaf', Edukasi Islam, Jurnal Pendidikan Islam, vol. 07, no. 1, 2018, pp. 67-100 [https://doi.org/10.30868/EI.V7].

Saeed, Abdullah, Menyoal Bank Syariah: Kritik Atas Interpretasi Bunga Bank Kaum Neo-Revivalis, ed. by Arif Maftuhin, Jakarta: Paramadina, 2004.

Shihab, M. Quraish, Al Lubab: Makna, Tujuan, dan Pelajaran dari Surah- Surah A-lQur'an, Tangerang: Lentera Hati, 2012.

Shihab, M. Quraisy, Tafsir al-Mishbah: Pesan, Kesan dan Keserasian al-Qur'an, 7th edition, Jakarta: Lentera Hati, 2002.

Thohier, Mahmud, 'Kajian Islam Tentang Akhlak dan Karakteristiknya', Jurnal Mimbar, vol. Volume XXI, no. Nomor 1, 2007, pp. 1-14 [https://doi.org/10.29313/mimbar.v23i1.231].

Yulianto, Firman K. and dkk, 'Analisis Pengaruh Faktor Bauran Pemasaran terhadap Pertimbangan Nasabah dalam Memilih Bank Syariah di Kota Medan', Wacana, vol. 13, no. 4, 2010, pp. 537-551 [https://doi.org/10.1017/CBO9781107415324.004].

Zaroni, Akhmad Nur, ‘Bisnis Dalam Perpsektif Islam (Telaah Aspek Keagamaan dalam Kehidupan Ekonomi)’, Mazahib, vol. 4, no. 2, 2007, pp. 172-184. 